\title{
Rhizon Sampling of Pore Waters on Scientific Drilling Expeditions: An Example from the IODP Expedition 302, Arctic Coring Expedition (ACEX)
}

by Gerald R. Dickens, Martin Koelling, David C. Smith, Luzie Schnieders, and

\section{Introduction}

For more than 35 years, interstitial water (IW) samples have been collected from sediment recovered during marine scientific coring expeditions. Pioneering work of DSDP and ODP quickly demonstrated that pore water chemistry differed from that of overlying seawater and from one location to another for myriad reasons (Sayles and Manheim, 1975). Extraction and analysis of IW samples has now become routine on deep-sea drilling cruises; the ensuing pore water profiles are being used to understand a range of processes, such as subsurface fluid flow (e.g., Brown et al., 2001; Saffer and Screaton, 2003), mineral diagenesis (e.g., Rudnicki et al., 2001; Malone et al., 2002), microbial reactions (e.g., Böttcher and Khim, 2004; D’Hondt et al., 2004), gas hydrate dissociation (e.g., Egeberg and Dickens, 1999; Tréhu et al., 2004), and glacial to interglacial changes in the composition of bottom water (e.g., Paul et al., 2001; Adkins and McIntyre, 2002).

The procedure for obtaining IW samples has continued relatively unchanged since early DSDP expeditions (Manheim and Sayles, 1974; Gieskes etal., 1991). Immediately after recovery, a short length of sediment (typically $5-15 \mathrm{~cm}$ long) is cut from a core along with its surrounding liner. This "whole-round" interval is taken to a laboratory, where the sediment plug is extruded from the liner, scraped to remove contamination, and placed inside a squeezer, where pressure is applied with a hydraulic press. Emerging waters are filtered, collected, and dispensed into aliquots for analyses.

Geochemists and microbiologists increasingly desire "high-resolution" pore water profiles, especially within 50-100 m of the seafloor (e.g., Egeberg and Dickens, 1999; Paul et al., 2001; Adkins and McIntyre, 2002; D'Hondt et al., 2004), and this often necessitates IW samples spaced every $2 \mathrm{~m}$ or less. Such whole-round squeezing comes with two

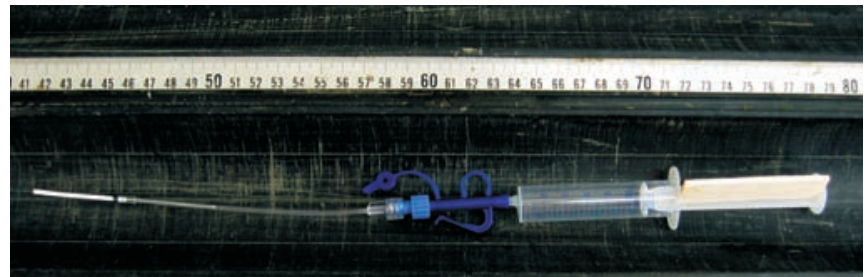

Figure 1. A Rhizon MOM 5-cm soil sampler with tube connector and syringe propped open with a wooden spacer major problems. First, it demands considerable labor and time, and secondly and most critically, the removal of wholerounds destroys the sedimentary record. High-resolution IW sampling, although desirable, will not happen at most sites unless non-destructive techniques are developed to collect numerous good samples with minimal effort.

Rhizon samplers (discussed below) are thin tubes of hydrophilic porous polymer designed to extract water from porous sediment using a vacuum. Unlike the aforementioned squeezing or some other common IW collection methods (e.g., centrifuging, pressurized gas) that "push" water from discrete sediment samples, Rhizon samplers "pull” water from intact sediment, thereby preserving the sedimentary record. They are also inexpensive and disposable, which eliminates the intensive cleaning steps associated with squeezers. Several studies have used Rhizon samplers to obtain waters from terrestrial soils (e.g., Knight et al., 1998; Tye et al., 2003). Recently, they have been successfully used to obtain pore waters from marine sediment collected in a gravity core or below a benthic chamber (Seeberg-Elverfeldt et al., 2005). Here, we evaluate and discuss the first use of Rhizon samplers on drill cores. The chosen cruise, Expedition 302 of the Integrated Ocean Drilling Program (IODP), is significant because its paleoceanographic objectives precluded collection of numerous IW samples by conventional methods.

\section{Pore Water Problem and Rhizon Solution}

IODP Expedition 302 was designed to reconstruct the Cenozoic oceanographic history of the central Arctic Ocean (Backman et al., 2006) One specific aim within this broad goal was an understanding of the sedimentary manganese record in the first $10-50 \mathrm{~m}$ below seafloor (mbsf). Piston cores from the central Arctic Ocean show a series of solidphase manganese spikes, which may record past changes in bottom water redox conditions (Li et al., 1969; Jakobsson et al., 2000).

A full appreciation of sedimentary manganese spikes requires complementary dissolved $\mathrm{Mn}^{2+}$ profiles (e.g., Burdige and Gieskes, 1983; Wallace et al., 1988), however, the requisite pore water sampling to generate such a profile presented a challenge for Expedition 302. Preservation of continuous core was desired to address first priority expedition objectives. Construction of an appropriately 
detailed dissolved $\mathrm{Mn}^{2+}$ profile in shallow sediment was therefore incompatible with Expedition 302 operations using traditional means for collecting IW samples.

Rhizon samplers present an unconventional method to collect IW samples from drill cores. In general, a Rhizon sampler consists of four parts (Seeberg-Elverfeldt et al., 2005): (1) a thin tube comprised of hydrophilic polymer, (2) a wire to support the tube, (3) a flexible hose to pass water from the tube, and (4) a connector. The porous tube is inserted into the sediment, and an evacuated container is attached to the connector. Pore water then passes from sediment through the porous tube and flexible hose into the collection chamber. Given a sufficiently small tube pore size $(0.1 \mu \mathrm{m})$, the Rhizon sampler also serves as a filter, removing microbial and colloidal contamination (Knight et al., 1998).

For Expedition 302, we selected Rhizon MOM $5 \mathrm{~cm}$ soil samplers (Fig. 1). These have an outer diameter of $2.4 \mathrm{~mm}$, a length of $5 \mathrm{~cm}$, a minimum pore size of $0.1 \mu \mathrm{m}$, a nylon supporting wire, and a PVC hose with a female luer-lock connector. They were the same as those used by SeebergElverfeldt et al. (2005).

Rhizon samplers collect interstitial water most efficiently when their pores are saturated with water prior to insertion. For Expedition 302, porous tubes were submerged in a beaker of deionized water for at least 30 minutes before use. Each Rhizon nominally contained $0.5 \mathrm{~mL}$ of deionized water before IW sampling.

\section{Site and Sample Collection}

IODP Expedition 302 drilled five holes at four sites on the Lomonosov Ridge at $\sim 88.5^{\circ} \mathrm{N}$ latitude, $136-140^{\circ} \mathrm{E}$ longitude, and in 1206-1288 $\mathrm{m}$ water depth (Backman et al., 2006). The five holes (M0002A, M0003A, and M0004A-C) have been grouped together as a single drill site because they are proximal, and because seismic reflection profiles show the same basic stratigraphy at each hole (Backman et al., 2006). Collectively, cores ( 4.5 $\mathrm{m}$ in length) recovered at this site span a 428-m-thick Campanian to Recent sedimentary sequence with several hiatuses. In this paper, we restrict discussion to the upper $50 \mathrm{mbsf}$ because this is where we employed the Rhizon samplers. Sediment in this interval comprises soft, silty clay of Latest Pliocene to Recent age (Backman et al., 2006).

Cores were passed down a Geotek logger immediately after recovery to establish basic physical properties (sonic velocity, magnetic susceptibility, gamma attenuation and resistivity). Once initially logged, IW samples were obtained by two methods: (1) cutting of whole-round intervals and squeezing, and (2) Rhizon sampling of intact cores. Cores were logged again after several hours.

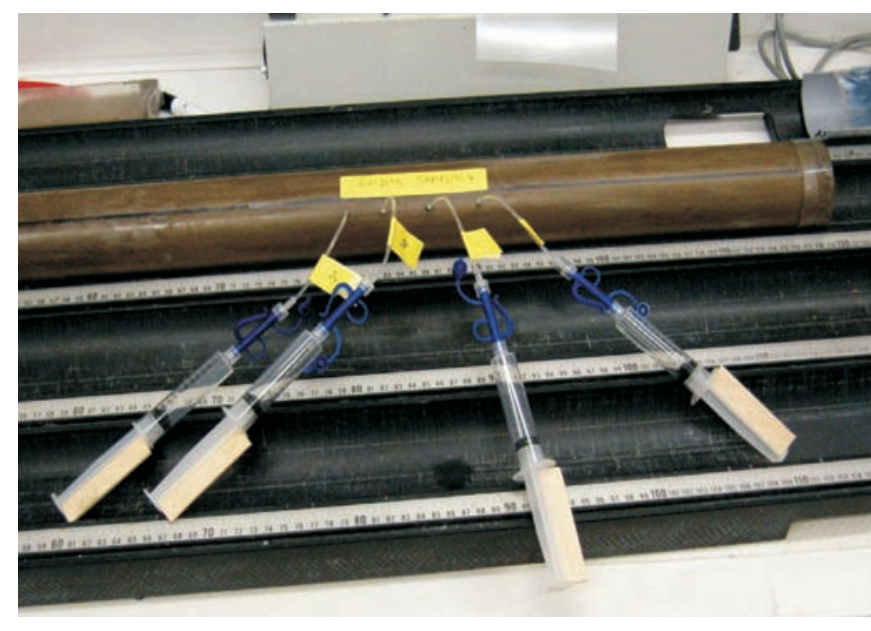

Figure 2. Four Rhizon samplers collecting water under vacuum from a 10-cm interval of a shallow core.

Whole-round intervals of approximately 5-10 cm length were taken every third or fourth core. The overall procedure (Backman et al., 2006) was similar to standard IODP protocol, with one notable exception. Because samples were taken after logging, there was a 30 to 40 minute delay in processing. However, this time lag probably did not modify pore water chemistry (at least relative to IW collection on previous expeditions) because temperatures of the shallow water column and ship deck were very low $\left(<5^{\circ} \mathrm{C}\right)$. In total, seven IW samples were taken over the upper $50 \mathrm{mbsf}$, similar to the resolution on many deep-sea coring expeditions.

While cores equilibrated for re-logging, intervals were selected on the designated working half of core sections for Rhizon sampling. For these intervals, between one and four 5 -mm-diameter holes were drilled through the core liner 1-2.5 cm apart (Fig. 2). The number and distances were adjusted to assess the minimum number of samplers required and "effective sampling distance". Saturated Rhizon samplers were wiped clean to remove excess water, and inserted through the holes so the porous tube was just buried. A tube connector with double luer-locks was connected to each Rhizon sampler, and then a $10-\mathrm{mL}$ syringe was attached to each tube connector, pulled to generate a vacuum, and held open with a spacer (Seeberg-Elverfeldt et al., 2005). Cores were then turned so that water along the inside of core was at the bottom and away from the Rhizon samplers. The initial $1-\mathrm{mL}$ in each syringe was discarded, while the rest was retained. In cases where Rhizons were taken $<10 \mathrm{~cm}$ apart, water samples were pooled to make one IW sample. In total, thirty-nine Rhizon IW samples were taken over the upper 50 meters drilled.

After collection of IW samples, aliquots were taken for various chemical analyses, depending on the total amount of water. The methodology and results of these analyses are presented by Backman et al. (2006), although we briefly note the analytical technique for the two sets of measurements presented here. Dissolved ammonium $\left(\mathrm{NH}_{4}^{+}\right)$was determined on $0.5-\mathrm{mL}$ aliquots at sea using the "Teflon tape gas separator method" (Hall and Aller, 1992); dissolved $\mathrm{Mn}^{2+}$ 
was determined on dilutions of 5 -mL aliquots treated with ultra-pure concentrated $\mathrm{HNO}_{3}$ in the Department of Geosciences, University of Bremen, using Inductively Coupled Plasma Optical Emission Spectrometry (ICP-OES).

\section{Results and Discussion}

Repeated tests showed that deionized water flows through Rhizons at $>10 \mathrm{~mL} \mathrm{~h}^{-1}$. This rate slowed considerably to $0.3-3.0 \mathrm{~mL} \mathrm{hr}^{-1}$ when Rhizons were placed into sediment. Moreover, there was a quasi-exponential decay in flow with core depth (Fig. 3), which probably relates to physical properties (e.g., decreasing porosity and permeability). Water did not flow appreciably from cores at $>50 \mathrm{mbsf}$; however, Rhizon samples from $<50$ mbsf rendered IW samples of sufficient volume for chemical analyses. This was especially true after adjacent Rhizon samples were pooled. In most cases, at least $10 \mathrm{~mL}$ of pore fluid could be collected from four adjacent Rhizon samplers within 5 hours. It was interesting to note that multiple Rhizons did not appear to impede water flow over this time interval unless spaced about $1 \mathrm{~cm}$ apart. This is consistent with tests and modeling results conducted by Seeberg-Elverfeldt et al. (2005).

Water obtained from Rhizons had a similar chemistry to that obtained from conventional squeezing over the upper $25 \mathrm{mbsf}$ (and perhaps $50 \mathrm{mbsf}$ ), considering experimental caveats. This was true for all dissolved species examined, but highlighted here for $\mathrm{NH}_{4}^{+}$and $\mathrm{Mn}^{2+}$ (Fig. 3). However, the time and energy expended to collect all thirty-nine Rhizon samples were much less than that for the seven squeezed samples.

Diffusion should dominate pore fluid profiles on Lomonosov Ridge, given the absence of significant tectonic compression and the generally low compaction rates (Backman et al., 2006). Consequently, smooth pore water

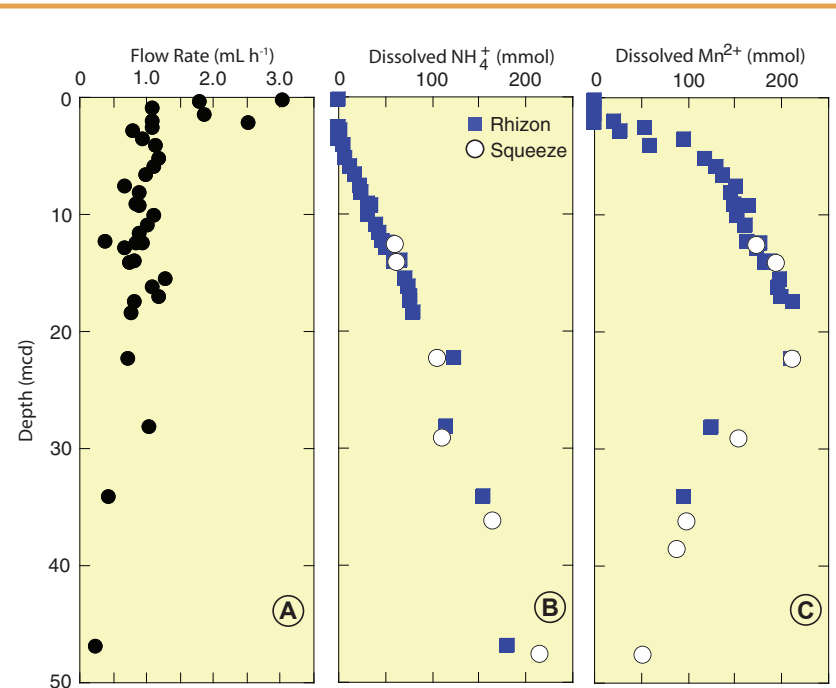

Figure 3. Downcore profiles of water sampling and analyses for the upper $50 \mathrm{~m}$ below seafloor on IODP Leg 302. [A] Fluid flow rate into Rhizon samplers averaged across examined sediment intervals. [B] Dissolved ammonium. [C] Dissolved manganese. concentration profiles should be expected, except across zones of chemical reaction (D'Hondt et al., 2004). This is true for all species analyzed using Rhizon samples on IODP Expedition 302, especially after adjusting core depths between the five holes from mbsf to mcd (meters composite depth; Backman et al., 2006). For $\mathrm{NH}_{4}^{+}$and $\mathrm{Mn}^{2+}$, the constructed depth profiles displayed smooth trends in concentration and clear changes in concentration gradients, notably the concave-up inflections between 3 and $5 \mathrm{mcd}$ (Fig. 3). These are most likely short depth intervals where $\mathrm{NH}_{4}^{+}$and $\mathrm{Mn}^{2+}$ are consumed, probably via microbial reactions. These inflections would have been missed with conventional pore water collection because of sampling resolution.

Cores recovered from adjacent deep-sea holes often display lithological and physical property changes offset in terms of recorded depth below the seafloor, presumably because of imperfect coring and differential core expansion (e.g., Hagelberg et al., 1995). Some of the offset in the Rhizon generated pore water profiles on Expedition 302 (Fig. 3) may reflect subtle misalignments of physical property measurements among the five holes. It is conceivable that, in regions where pore waters display obvious diffusion gradients, sediment cores from adjacent holes could be aligned, beyond physical property measurements, by using high-resolution pore water profiles obtained by Rhizons.

Other than the shallow depth restriction, there appears to be only one minor problem with Rhizon sampling of deepsea sediment cores. After Rhizons are inserted, some intervals showed a slight drop in P-wave velocity of sediment. The simplest explanation is that extraction of water from the sediment causes the core to shrink, leaving air space between the sediment and the core liner.

\section{Acknowlegements}

We sincerely thank the captains and crews of the three ice-breaking ships (Oden, Vidar Viking, and Sovetskiy Soyuz) involved in the ACEX cruise, along with the ice management and drilling teams. Without the collective efforts of these people, we would still lack drill cores from the central Arctic Ocean, let alone a test of Rhizon samplers. We also thank the co-chief scientists Jan Backman and Kate Moran, who enthusiastically gave us permission to test Rhizon samplers in precious cores.

\section{References}

Adkins, J.F., and McIntyre, K., 2002. The salinity, temperature, and ${ }^{818} \mathrm{O}$ of the glacial deep ocean. Science, 298:1769-1773.

Backman, J., Moran, K., McInroy, D.B., Mayer, L.A., and the Expedition 302 Scientists, 2006. Proc. IODP, 302. doi:10.2204/iodp.proc.302.101.2006

Böttcher, M.E., Khim, B.-K., Suzuki, A., Gehre, M., Wortmann, U.G., and Brumsack, H.-J., 2004. Microbial sulfate reduction in 
deep sediments of the Southwest Pacific (ODP Leg 181, Sites 1119-1125): Evidence from stable sulfur isotope fractionation and pore water modeling. Mar. Geol., 205: 249-260.

Borowski, W.S., Paull, C.K., and Ussler, W., 1999. Global and local variations of interstitial sulfate gradients in deep-water, continental margin sediments: Sensitivity to underlying methane and gas hydrates. Mar. Geol., 159:131-154.

Brown, K.M., Saffer, D.M., and Bekins, B.A., 2001. Smectite diagenesis, pore-water freshening, and fluid flow at the toe of the Nankai wedge. Earth Planet. Sci. Lett., 194:97-109.

Burdige, D.J., and Gieskes, J.M., 1983. A pore water/solid phase diagenetic model for manganese in marine sediments. Amer. J. Sci., 283: 29-47.

D’Hondt, S., Jørgensen, B.B., Miller, D.J., Batzke, A., Blake, R., Cragg, B.A., Cypionka, H., Dickens, G.R., Ferdelman, T., Hinrichs, K-U., Holm, N.G., Mitterer, R., Spivack, A., Wang, G., Bekins, B., Engelen, B., Ford, K., Gettemy, G., Rutherford, S.D., Sass, H., Skilbeck, C.G., Aiello, I.W., Guèrin, G., House, C.H., Inagaki, F., Meister, P., Naehr, T., Niitsuma, S., Parkes, R.J., Schippers, A., Smith, D.C., Teske, A., Wiegel, J., Padilla, C.N., and Acosta, J.L.S., 2004. Distributions of microbial activities in deep subseafloor sediments. Science, 30: 2216-2221.

Egeberg, P.K., and Dickens, G.R., 1999. Thermodynamic and pore water halogen constraints on gas hydrate distribution at ODP Site 997 (Blake Ridge). Chem. Geol., 153:53-79.

Gieskes, J.M., Gamo, T., and Brumsack, H., 1991. Chemical methods for interstitial water analysis aboard JOIDES Resolution. ODP Tech. Note: 15 .

Hagelberg, T.K., Pisias, N.G., Shackleton, N.J., Mix, A.C, and Harris, S., 1995. Refinement of a high-resolution, continuous sedimentary section for studying equatorial Pacific Ocean paleoceanography. Proc. ODP, Sci. Res., 138:31-46.

Hall, P.O.J., and Aller, R.C., 1992. Rapid small-volume flow injection analysis for $\mathrm{CO} 2$ and $\mathrm{NH} 4$ in marine sediments. Limnol. Oceanogr., 35: 1113-1115.

Jakobsson, M., Lovlie, R., Al-Hanbali, H., Arnold, E., Backman, J., and Morth, M., 2000. Manganese and color cycles in Arctic Ocean sediments constrain Pleistocene chronology. Geology, 28:23-26.

Knight, B.P., Chaudri, A.M., McGrath, S.P., and Giller, K.E., 1998. Determination of chemical availability of cadmium and zinc in soils using inert soil moisture samplers. Environ. Pollut., 99: 293-298.

Li, Y.-H., Bischoff, J., and Mathieu, G., 1969. Migration of manganese in Arctic Basin Sediment Earth Planet. Sci. Lett., 7: 265-270.

Malone, M.J., Claypool, G., Martin, J.B., and Dickens, G.R., 2002. Variable methane fluxes in shallow marine systems over geologic time: The composition and origin of pore waters and authigenic carbonates on the New Jersey shelf. Mar. Geol., 189:175-196.

Manheim, F.T., and Sayles, F.L., 1974. Composition and origin of interstitial waters of marine sediments, based on deep sea drill cores. In Goldberg, E.D. (Ed.), The Sea (Vol. 5): Marine Chemistry: The Sedimentary Cycle: New York (Wiley), 527-568.
Paul, H.A., Bernasconi, S.M., Schmid, D.W., and McKenzie, J.A., 2001. Oxygen isotopic composition of the Mediterranean Sea since the last glacial maximum: Constraints from pore water analyses. Earth Planet. Sci. Lett., 192:1-14.

Rudnicki, M.D., Wilson, P.A., and Anderson, W.T., 2001. Numerical models of diagenesis, sediment properties, and pore fluid chemistry on a paleoceanographic transect; Blake Nose, Ocean Drilling Program Leg 171B. Paleoceanogr., 16: 563-575.

Saffer, D.M., and Screaton, E.J., 2003. Fluid flow at the toe of convergent margins; interpretation of sharp pore-water geochemical gradients. Earth Planet. Sci. Lett., 213: 261-270.

Sayles, F.L., and Manheim, F.T., 1975. The interstitial solutions and diagenesis in deeply buried marine sediments: Results from deep-sea drilling project. Geochim. Cosmochim. Acta, 39: 103-127.

Seeberg-Elverfeldt, J., Schlüter, M., Feseker, T., and Kölling, M., 2005. A Rhizon in situ sampler (RISS) for pore water sampling from aquatic sediments. Limnol. Oceanogr. Meth., 3: $361-371$.

Tréhu, A.M., Bohrmann, G., Rack, F.R., Torres, M.E., Bangs, N.L., Barr, S.R., Borowski, W.S., Claypool, G.E., Collett, T.S., Delwiche, M.E., Dickens, G.R., Goldberg, D.S., Gràcia, E., Guèrin, G., Holland, M., Johnson, J.E., Lee, Y-J., Liu, C-S., Long, P.E., Milkov, A.V., Riedel, M., Schultheiss, P., Su, X., Teichert, B., Tomaru, H., Vanneste, M., Watanabe, M., and Weinberger, J.L., 2004. Three-dimensional distribution of gas hydrate beneath southern Hydrate Ridge: Constraints from ODP Leg 204. Earth Planet. Sci. Lett., 222:845-862.

Tye, A.M., Young, S.D., Crout, N.M., Zhang, H., Preston, S., BarbosaJefferson, V.L., Davison, W., McGrath, S.P., Paton, G.I., Kilham, K., and Resende, L., 2003. Predicting the activity of $\mathrm{Cd}^{2+}$ and $\mathrm{Zn}^{2+}$ in soil pore water from the radio-labile metal fraction. Geochim. Cosmochim. Acta, 67:375-385.

Wallace, H.E., Thomson, J., Wilson, T.R.S., Weaver, P.P.E., Higgs, N.C., and Hydes, D.J., 1988. Active diagenetic formation of metal-rich layers in NE Atlantic Sediments. Geochim. Cosmochim. Acta, 52:1557-1569.

\section{Authors}

Gerald R. Dickens, Department of Earth Sciences, Rice University, Houston, Texas 77005, U.S.A., e-mail: jerry@rice.edu

Martin Kölling, Department of Geosciences, University of Bremen, 28359 Bremen, Germany.

David C. Smith, Graduate School of Oceanography, University of Rhode Island, Narragansett, R.I. 02882, U.S.A. Luzie Schnieders, Department of Geosciences, University of Bremen, 28359 Bremen, Germany. 